Çukurova Üniversitesi Mühendislik Fakültesi Dergisi, 36(2), ss. 331-345, Haziran 2021

Cukurova University Journal of the Faculty of Engineering, 36(2), pp. 331-345, June 2021

\title{
Jet Giriş Genişliğinin Isı Transferi ve Akış Yapısına Olan Etkisinin Araştırılması
}

\author{
Doğan Engin ALNAK ${ }^{1}$, Koray KARABULUT ${ }^{* 2}$, \\ ${ }^{1}$ Sivas Cumhuriyet Üniversitesi, Teknoloji Fakültesi, Otomotiv Mühendisliği Bölümü, Sivas \\ ${ }^{2}$ Sivas Cumhuriyet Üniversitesi, Sivas Teknik Bilimler Meslek Yüksekokulu, Elektrik ve Enerji \\ Bölümü, Doğalgaz ve Tesisatı Teknolojisi Programı, Sivas
}

Geliş tarihi: 29.03 .2021

Kabul tarihi: 30.06 .2021

\section{$\ddot{\mathbf{O z}}$}

Bu çalışmada, farklı jet giriş genişliklerindeki kanallarda bulunan düz yamuk ve ters yarım daire şeklinde iki farklı desene sahip bakır plakalı yüzeylerden hava jeti akışı ile olan ısı transferi sayısal olarak araştırılmıştır. Sayısal hesaplamalar, zamandan bağımsız ve üç boyutlu olarak enerji ve Navier-Stokes denklemlerinin k- $\varepsilon$ türbülans modelli Ansys-Fluent bilgisayar programı kullanılarak çözülmesiyle gerçekleştirilmiştir. Kanalların üst ve alt yüzeyleri adyabatik olup desenli yüzeylere sabit 1sı akısı uygulanmıştır. Jet giriş genişlikleri $\mathrm{D}_{\mathrm{h}}$ ve $1,25 \mathrm{D}_{\mathrm{h}}$ 'dır. Çalışmanın sonuçları, literatürdeki çalışmanın sayısal ve deneysel sonuçlarıyla karşılaştırılmış ve birbirleriyle uyumlu oldukları görülmüştür. Sonuçlar, her bir desenli yüzey için ortalama $\mathrm{Nu}$ sayısı ve yüzey sıcaklık değişimi olarak sunulmuştur. Jet ve plaka arası mesafe $\left(H / D_{h}\right)$ 12'de $R e=9000$ için ters yarım daire desenli yüzeylerin ortalama $\mathrm{Nu}$ sayıs1, düz yamuk desenli yüzeylerden yaklaşık \%56 daha fazladır.

Anahtar Kelimeler: Jet giriş genişliği, Çarpan hava jeti, Desenli yüzey, Isı transferi

\section{Search of the Effect of Jet Inlet Width on Heat Transfer and Flow Character}

\begin{abstract}
In this study, the heat transfer was numerically researched by air jet flow from copper plate surfaces having different pattern shapes as flat trapezoid and reverse semi-circular in channels with different jet inlet widths. Numerical calculations were performed by solving the energy and Navier-Stokes equations in three dimensions and steady, using the Ansys-Fluent program with standard k- $\varepsilon$ turbulence model. The top and bottom facets of the channels are adiabatic and fixed heat flux was implemented to the patterned facets. Jet entrance widths are $D_{h}$ and $1,25 D_{h}$. The results of the study were compared with the numerical and experimental results of the work in the literature and it was obtained that they are compatible with one another. The results were exhibited as the average Nu number and variation of facet temperature for each patterned facet. The average $\mathrm{Nu}$ number of reverse semi-circular patterned facets is approximately $56 \%$ more than flat trapezoid patterned facets at distance between jet-plate $\left(\mathrm{H} / \mathrm{D}_{\mathrm{h}}\right) 12$ for $\mathrm{Re}=9000$.
\end{abstract}

Keywords: Jet entrance width, Impingement air jet, Patterned facet, Heat transfer

*Sorumlu yazar (Corresponding author): Koray KARABULUT, kkarabulut@cumhuriyet.edu.tr 


\section{GíRiș}

Çarpan jet akışı, püskürtücüden yüzeye jet akışını içermektedir. Çarpan jetin 1sı transferi, genellikle geleneksel yöntemlerle elde edilenden daha fazladır. Katı yüzeyi ısıtmak veya soğutmak için kullanılan yaygın bir yöntemdir [1]. Çarpan jet tekniğine metallerin sertleştirilmesi, türbin kanatçıklarının soğutulması işlemlerinde [2] ve güneş hücrelerin soğutulması gibi çok çeşitli sanayi uygulamalarında başvurulmaktadır [3]. Bunlardan başka, jet ile soğutma günümüzde yüksek kapasiteli elektronik 1sıl sistemler için kullanılabilir bir uygulama durumuna gelmiştir. Isı üretim miktarı fazla olan elektronik ekipmanlar, daima teknolojik gelişime uğradığı, hacimsel olarak küçüldüğü ve geliştiği için tekil olarak hava ile soğutularak kullanılabilmesinin gerekli ve yeterli kapasiteyi sağlayamayacağı saptanmıştır. Soğutma işleminin çarpan jet ile yapılmasıyla fazla 1s1 akılı bu elemanlardan yüksek miktarlarda 1sının transferi olanaklı hale gelmektedir [4,5].

Çarpan jet akışı hakkındaki daha önce gerçekleştirilen çalışmaların birinde, Carlomagno ve Ianiro [6] 1sı transferi ve çarpan jet akış karakteristiği üzerinde $\operatorname{Re}$ sayısı ile jet ve plaka arası mesafenin etkisini detaylı bir şekilde incelemişlerdir. Çalışmalarını PIV (parçacık görüntülemeli hı ölçüm) tekniği ile gerçekleştirmişlerdir. Ayrıca, PIV sonuçlarını ileri hesaplama yöntemleriyle de kıyaslamışlardır. Argus ve arkadaşları [7] laminer hava jeti akışı ile bir kanaldaki 1sınmış blokların 1S1 transferini sayısal olarak araştırmışlardır. Çalışmalarında, jet Re sayısının, kanal yüksekliğinin, jetin delik genişliğinin, soğutulan plakalar arası uzaklığın, plakaların yükseklik ve 1sı iletim katsayılarının etkisini değerlendirmişlerdir. Genel itibariyle, blokların etkin olarak soğutulmasının azalan kanal yüksekliği ve artan $\operatorname{Re}$ sayısı ile mümkün olabileceğini bulmuşlardır. Popovac ve Hanjalic [8] çarpan jet akışı uygulamasıyla küp şeklindeki bir plaka için ısı transferini incelemişlerdir. Ayrıca, küp etrafındaki akış özelliklerini araştırmışlar ve küpten olan 1sı transferi ile akış yapısı arasında doğrudan bir ilişkinin var olduğunu belirlemişlerdir. Yang ve Hwang [9] yarı silindirik şeklinde dış bükey bir yüzey üzerine çarpan türbülans özellikli bir jet akışını sayısal olarak incelemişler ve artan Re sayısı ile yüzeydeki hız değişimi ve türbülans kinetik enerjide artış saptamışlardır. Karabulut ve Alnak [10] sur ve dikdörtgen şeklinde olmak üzere iki farklı desene sahip sabit 1s1 akılı bakır plakalı yüzeylerin tek bir hava jeti akışı ile soğutulmasının sayısal araştırmasını yapmışlardır. Değişken parametreler olarak jet-plaka arası uzaklığı ve Re sayısını kullanmışlardır. Çalışmalarında, $\mathrm{Re}=4000$ ve jetplaka arası uzaklık değeri 4 için sur deseni şeklindeki yüzeylere göre dikdörtgen desen şeklindeki yüzeylerde ortalama $\mathrm{Nu}$ sayısında \%31,45'lik fazladan bir artış elde etmişlerdir. Bir diğer çalışmada, Karabulut [11] dikdörtgen kesitli kanallar içerisinde 1sıttılmış beşer adet ters ve düz daire şeklindeki desenli yüzeylerin hava jeti akışı ile soğutulmasını sayısal hesaplamalı olarak incelemiştir. Desenli yüzeylerin soğutma performansları üzerinde desen şeklinin ve jet-plaka arası mesafenin Re sayısına göre daha büyük bir öneme sahip olduğunu belirlemiştir. Mushatat [12] çarpan jetler için 1sı transferi ve akış yapılarını sayısal hesaplamalı olarak incelemiştir. Bununla birlikte, jetin Re sayısının ve jetler arası uzaklığın $\mathrm{Nu}$ sayısı ve türbülans kinetik enerji değerlerini önemli ölçüde etkilendiğini belirlemiştir. Tepe [13] yarı dairesel bir iç bükey yüzey üzerinde kademeli dizi halinde çarpan jet soğutmasını sayısal olarak araştırmıştır. Sayısal hesaplamalarını farklı Re sayıları, jet-plaka arası uzaklıkları ve jet lülesi ve plaka arasındaki mesafeyi değerlendirerek yapmıştır. Sonuçlarında, ortalama ve noktasal $\mathrm{Nu}$ sayılarının jet lülesi ve plaka arasındaki mesafenin azalmasıyla arttığını belirlemiştir. Belarbi ve arkadaşları [14] ise bilgisayar işlemcisi soğutma kapasitesini artırmak amacıyla çarpan hava jetini kullanarak soğutucu bloğun isıl ve aerodinamik performanslarını deneysel olarak incelemişlerdir. Bunu yaparken hız gradyanı, 1sıl direnç ve sicaklık değişimi üzerinde çarpan jetin uzaklığının etkisini de araştırmışlardır. Bunun yanında, ısıl performans üzerinde bilgisayar işlemcisinin yerleştirilme konumunu da değerlendirmişlerdir. Sonuçlar, jet yüksekliği/çap oranı (Y/D) için 0,606 değeriyle en iyi soğutma performansına ulaşıldığını ve işlemci ünitesinin gerçek konumundan boylamasına $10 \mathrm{~mm}$ mesafe kadar konum değiştirmesinin soğutma kapasitesini iyileştirdiğini göstermiştir. 
Leena ve arkadaşları [15] düz bakır bir plaka üzerine birden çok hava jeti çarpmasının soğutma performans1 özelliklerini deneysel ve sayısal olarak incelemişlerdir. Sayısal çalışma için AnsysFluent bilgisayar programını kullanırken, deneysel inceleme için ayrı bir sistem planlamışlardır. Simülasyonu yapılmış olan bir işlemcinin 1sı transfer yüzeyi olarak tabandan isitılan bakır bir plakadan yararlanılmış ve sistemde sıralı jetler bir hat şeklinde düzenlenmiştir. Isı transferi miktarında Re sayısı ve jetler arası uzaklığın etkisini sayısal olarak araştırmışlar ve aynı zamanda, sayısal çalı̧̧ma sonuçlarını deneysel sonuçlarla kıyaslamışlardır.

Sunulan çalışmada elektronik endüstrisinin en küçük birimi olup, bilgisayarlarda da kullanılan mikroçiplerden olan 1S1 transferini artırmak amacıyla dikdörtgen kesitli kanallar içerisindeki düz yamuk ve ters yarım daire şeklinde farklı desenlere sahip bakır plakalı yüzeylerin farklı jet genişliklerinde hava jeti akışı ile 1 sı transferinin sayısal incelemesi yapılmıştır. Sayısal inceleme, zamandan bağımsız, üç boyutlu olarak enerji ve Navier-Stokes denklemlerinin k- $\varepsilon$ türbülans modelli Ansys-Fluent bilgisayar programının kullanılarak çözülmesiyle gerçekleştirilmiştir. Çalışmada, literatürdeki uygulamalar da gözetilerek 50×200 mm ölçülerinde ve farkl yüksekliklere sahip dikdörtgen şeklindeki kanallar kullanılırken, çarpan jet akışkanı 300K kanal giriş sıcaklığı olan hava kullanılmıştır. $D_{h}$ ve $1,25 D_{h}$ olmak üzere jet akış giriş uzunluğu, jet-desenli yüzeyler arası uzaklıklar $\left(H / D_{h}\right)$, düz yamuk ve ters yarım daire olarak farklı geometrik desen şekilleri ve jet Re sayısı değişkenler olarak incelenmiştir. Araştırmada, desenli yüzeylere $1000 \mathrm{~W} / \mathrm{m}^{2}$ lik sabit bir 1s1 akısı uygulanmıştır. Çalışmada, jet Re sayısı aralığı 5000-11000 iken jet-desenli yüzeyler arası uzaklığı ise $6 \mathrm{D}_{\mathrm{h}}$ ve 12D $\mathrm{D}_{\mathrm{h}}$ 'dır. İncelenen çalışmanın sonuçları, literatürdeki çalışmanın deneysel ve sayısal sonuçlarıyla kıyaslanmış ve sonuçların uyumlu oldukları saptanmıştır. Ulaşılan sonuçlar, düz yamuk ve ters yarım daire olmak üzere desenli yüzeylerin her biri için ayrı ayrı ortalama $\mathrm{Nu}$ sayısı ve yüzey sıcaklık değişimleri olarak verilmiş ve birbirleriyle karşılaştırılmalı incelemesi yapılmıştır. Farklı jet giriş genişlikleri, $\mathrm{H} / \mathrm{D}_{\mathrm{h}}$ mesafeleri ve Re sayıları için jet akışın kanal içerisindeki sicaklık ve akım çizgisi konturu dağılımları desenli yüzeyler için analiz edilmiștir. Çalışmada ayrıca desenli geometrilerin farklı Re sayıları, jet-plaka uzaklıkları $\left(\mathrm{H} / \mathrm{D}_{\mathrm{h}}=3\right.$ ve 6$)$ ve jet giriş genişlikleri için tüm yüzeyler dikkate alınarak ortalama $\mathrm{Nu}$ sayısı $\left(\mathrm{Nu}_{0}\right)$, kanaldan jet akış çıkış sıcaklığı $\left(T_{j \xi s}\right)$ değerleri yorumlanmıştır.

\section{SAYISAL İNCELEME}

Çalışmada, üç boyutlu ve zamandan bağımsız olarak farklı şekillere sahip desenli yüzeyler üzerindeki jet akışın zorlanmış taşınım 1S1 transferinin sayısal olarak hesaplamalı çözümünde Ansys-Fluent programından yararlanılmıştır.

Süreklilik ve momentum denklemleri için yakınsama ölçeği $10^{-6}$ olup, enerji denklemi için bu değer $10^{-7}$ dir. Simülasyonlarda kullanılan ağ yapısı şekli dörtyüzlüdür (tetrahedral). Ayrıca, çalışma literatürde bulunan diğer türbülans modelleriyle kıyaslandığında [16] üretilen kinetik enerjiyi azalttığı ve jet durma bölgesinde elde edilmesi gereken sonuca yaklaşıldı̆̆ından çalışmada standart $\mathrm{k}-\varepsilon$ türbülans modelinin kullanılmasının uygun olduğu belirlemiştir.

Kanaldaki akış ve 1S1 transferinin çözümüne aşağıda açıklandığı üzere gövde kuvvetinin bulunmadığ $\breve{g a r a r l}$ durumdaki türbülanslı akış için zaman ortalamalı kütle, momentum ve enerjinin korunumu denklemlerinden türetilen kısmi türevli diferansiyel denklemlerin çözümü ile ulaşılmıştır [16].

Süreklilik denklemi (Eşitlik 1):

$$
\frac{\partial \bar{u}_{i}}{\partial x_{j}}=0
$$

Momentum denklemi (Eşitlik 2):

$$
\begin{aligned}
& \rho \frac{\partial}{\partial x_{j}}\left(\bar{u}_{i} \bar{u}_{j}\right)=\frac{\partial \bar{P}}{\partial x_{i}}+ \\
& \frac{\partial}{\partial x_{j}}\left[\mu\left(\frac{\partial \bar{u}_{i}}{\partial x_{j}}+\frac{\partial \bar{u}_{i}}{\partial x_{j}}\right)-\rho \overline{u_{i}^{\prime} u_{j}^{\prime}}\right]
\end{aligned}
$$


Enerji denklemi (Eşitlik 3):

$$
\rho c_{p} \frac{\partial}{\partial x_{i}}\left(\bar{u}_{i} \bar{T}\right)=\frac{\partial}{\partial x_{i}}\left[k \frac{\partial \bar{T}}{\partial x_{i}}-\rho c_{p} \overline{T^{\prime} u_{i}^{\prime}}\right]
$$

Türbülans kinetik enerji denklemi (Eşitlik 4):

$$
\begin{aligned}
& \frac{\partial}{\partial x_{i}}\left(\rho k^{\prime} u_{i}\right)+\frac{\partial}{\partial y}\left(\rho k^{\prime}\right)=\frac{\partial}{\partial x_{j}}\left[\mu+\frac{\mu_{t}}{\sigma_{k}} \frac{\partial k^{\prime}}{\partial x_{j}}\right]+ \\
& G_{k}-\rho \varepsilon
\end{aligned}
$$

Türbülans kinetik enerji yutulma terimi (Eşitlik 5):

$$
\begin{aligned}
& \frac{\partial}{\partial x_{i}}\left(\rho \varepsilon u_{i}\right)+\frac{\partial}{\partial y}(\rho \varepsilon)=\frac{\partial}{\partial x_{j}}\left[\left(\mu+\frac{\mu_{t}}{\sigma_{\varepsilon}}\right) \frac{\partial \varepsilon}{\partial x_{j}}\right]+ \\
& C_{1 \varepsilon} \frac{\varepsilon}{k^{\prime}} G_{k}-C_{2 \varepsilon} \rho \frac{\varepsilon^{2}}{k^{\prime}}
\end{aligned}
$$

Bu denklemlerde $\rho$ akışkanın yoğunluğunu, k' türbülanslı akışın kinetik enerjisini, $\mathrm{u}_{\mathrm{i}}, \mathrm{x}, \mathrm{y}$ ve $\mathrm{z}$ eksenleri doğrultusundaki hız bileşenlerini, $\mu$ akışkanın viskozitesini, $\sigma_{\mathrm{k}}$ türbülanslı kinetik enerji Prandtl sayısını $\left(\sigma_{\mathrm{k}}=1\right)$ göstermektedir. Türbülanslı kinetik enerji üretimi $\left(\mathrm{G}_{\mathrm{k}}\right)$ ve türbülanslı akışın viskozitesini $\left(\mu_{\mathrm{t}}\right)$ veren eşitlikler aşağıda verilmiştir [17] (Eşitlik 6-7).

$$
\begin{gathered}
G_{k}=-\rho \overline{u_{i}^{\prime} u_{j}^{\prime}} \frac{\partial u_{j}}{\partial x_{i}} \\
\mu_{t}=C_{\mu} \rho \frac{k^{\prime 2}}{\varepsilon}
\end{gathered}
$$

$\mathrm{C}_{1 \varepsilon}, \mathrm{C}_{2 \varepsilon}$ ve $\mathrm{C}_{\mu}$ katsayıları, $\sigma_{\varepsilon}$ ise türbülans yutulma Prandtl sayisinı temsil etmektedir ve sirasiyla $\mathrm{C}_{1 \varepsilon}=1,44, \quad \mathrm{C}_{2 \varepsilon}=1,92, \mathrm{C}_{\mu}=0,09$ ve $\sigma_{\varepsilon}=1,3$ olarak alınmıştır [17]. $\mathrm{Bu}$ sabitlerin değerleri, birçok türbülanslı akış için çok sayıda veri uyumuyla elde edilmiştir.

Reynolds sayısı $(\mathrm{Re})$ aşağıda verilen denklem ile hesaplanmaktadır (Eşitlik 8).

$$
R e_{k}=\frac{V_{\infty} D_{h}}{v}
$$

Burada $\mathrm{D}_{\mathrm{h}}$, jet girişinin hidrolik çapıdır (Eşitlik 9).

$$
D_{h}=\frac{4 A_{c}}{P}=\frac{4(a . W)}{2(a+W)}
$$

$\mathrm{Bu}$ denklemde $\mathrm{A}_{\mathrm{c}}$ ve $\mathrm{P}$ sırasıyla jet girişinin kesit alanı ve çevre uzunluklarıdır. Nusselt sayısı $(\mathrm{Nu})$, taşınımla 1sı geçişinin iletimle 1sı geçişine oranı olarak değerlendirilir (Eşitlik 10).

$$
-k\left(\frac{\partial T}{\partial n}\right)_{s}=h\left(T_{\infty}-T_{s}\right) \text { ve } N u=\frac{h \cdot D_{h}}{k}
$$

Burada, h yüzey üzerindeki yerel $1 \mathrm{~s}$ 1 taşınım katsayısı, $\mathrm{n}$ ise yüzeye dik yöndür ve ortalama $1 \mathrm{~s} 1$ taşınım katsayısı $h_{m}$, ve ortalama $\mathrm{Nu}$ sayısı $\left(\mathrm{Nu}_{\mathrm{o}}\right)$ aşağıdaki gibi hesaplanmaktadır.

Ortalama 1sı taşınım katsayısı (Eşitlik 11):

$h_{m}=\frac{1}{L} \int_{0}^{L} h d x$

Ortalama Nu sayısı (Eşitlik 12):

$$
N u_{o}=\frac{h_{m} D_{h}}{k}
$$

Eşitlik 11 ve 12 'de $h$ ve $h_{m}$ sırasıyla noktasal ve ortalama ısı taşınım katsayılarını belirtmektedir.

\section{GEOMETRIK TASARIM}

Şekil 1'de çalışmada incelenen desenli yüzeylerin var olduğu kanalların ölçüleri ve kullanılan sınır şartları perspektif görünüşler üzerinde gösterilmektedir. Çalışmada $\mathrm{D}_{\mathrm{h}}$ ve $1,25 \mathrm{D}_{\mathrm{h}}$ olmak üzere iki farklı jet püskürtücü genişliği kullanılmış olup, hidrolik çap $\mathrm{D}_{\mathrm{h}}$ değeri 9,9 mm'dir. Kanal, $200 \mathrm{~mm}$ boy uzunluğuna (L) ve $50 \mathrm{~mm}$ genişliğe (W) sahiptir. Jet akışkanının püskürtücüden çıkan kanal giriş hızı aralığ $4,42-9,72 \mathrm{~m} / \mathrm{s}$ olup jet girişinde uniform hız profiline sahip dikdörtgen şeklindeki püskürtücünün ölçüleri 9,9x50 mm ve 
$12,375 \times 50 \mathrm{~mm}$ 'dir. Kanal yükseklikleri ise $6 \mathrm{D}_{\mathrm{h}}$ ve $12 \mathrm{D}_{\mathrm{h}}$ 'dır. İki ayrı kanal içerisinde yedi adet düz yamuk ve yedi adet ters yarım daire desenli yüzey bulunmakta iken desenler ardışı olarak tasarlanmıştır. Bununla birlikte, desenlerin genişlik ve yükseklikleri $2 D_{h}$ ve $D_{h}$ ' dir.

Bu çalışmada yapılan kabuller şunlardır:

a) Akış alanı üç boyutlu, zamandan bağımsız ve akış türbülanslıdır. b) Jet akışkanı sıkıştırılamaz havadır.

c) Desenli yüzey şekillerine sabit $1000 \mathrm{~W} / \mathrm{m}^{2}$ 1s1 akısı uygulanmıştır.

d) Jet akışkanın 1sıl özelikleri sabit ve kinematik viskozitesi $v=15,89 \quad 10^{-6} \mathrm{~m}^{2} / \mathrm{s}$, yoğunluğu $\rho=1,1614 \mathrm{~kg} / \mathrm{m}^{3}$, özgül $1 \mathrm{~s} 1 \mathrm{~s} 1 \mathrm{c}_{\mathrm{p}}=1,007 \mathrm{kj} / \mathrm{kgK}$, 1s1 iletim katsayısı $\mathrm{k}=26,310^{-3} \mathrm{~W} / \mathrm{mK}$ olarak alınmıştır.

e) Jet akışkanı ve desenli yüzeyler için ısı üretimi yoktur.
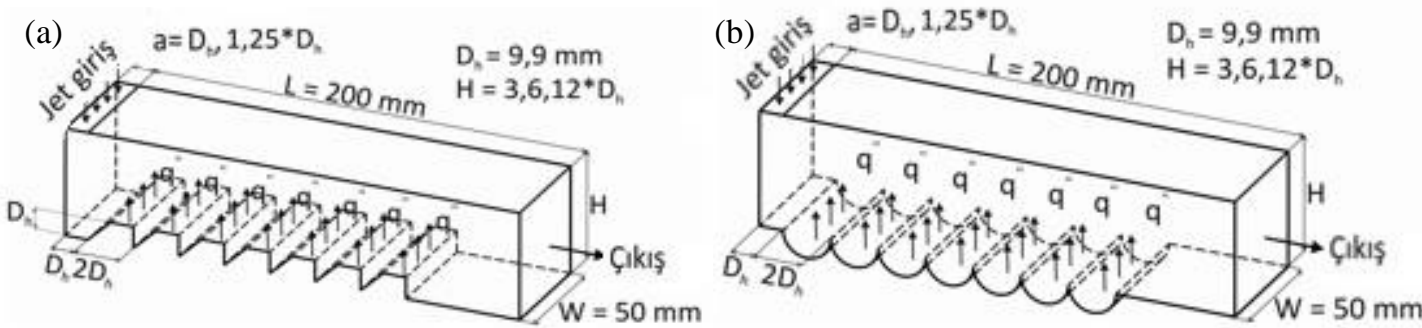

Şekil 1. Sınır şartları ve boyutları olan hesaplama hacimlerinin perspektif görünüşleri (a) düz yamuk desenli (b) ters yarım daire desenli

\section{SONUÇLARIN DEĞERLENDİRILLMESI}

Kılıç ve arkadaşları [18]'nın yaptıkları çalışmanın deneysel ve sayısal $\mathrm{Nu}$ sayısı sonuçları $\mathrm{H} / \mathrm{D}_{\mathrm{h}}=6$ ve Reynolds sayısının 6000 ve 8000 değerleri için olmak üzere bu çalışmanın sayısal sonuçlarıyla karşılaştırılmış ve elde edilen sonuçlar Şekil 2'de gösterilmiştir. Re=6000'de jetin çarpma bölgesindeki Nu sayısı değeri incelendiğinde Kılıç ve arkadaşları [18]'nın deneysel sonucu ile bu çalışmanın sayısal sonucu arasında \%3,99'luk bir fark varken, sayısal sonuçlar arasında \%1'lik bir fark olduğu belirlenmiștir. Bununla birlikte, $\mathrm{Re}=8000$ için çarpma bölgesinde türbülans yoğunluğunun artışına bağlı olarak Kılıç ve arkadaşları [18]'nın deneysel sonuçları ile bu çalışmanın sayısal sonuçları arasındaki fark artarak \%9,15 olmaktadır. Aynı bölgede, sayısal sonuçlar arasındaki fark ise \%1,02'dir. Ulaşılan bu sonuçlara göre, bu çalışmanın sayısal sonuçlarının Kılıç ve arkadaşları [18]'nın deneysel ve sayısal sonuçlarıyla kıyaslanabilir ve bu çalışmanın kabul edilebilir doğrulukta olduğu söylenebilmektedir.

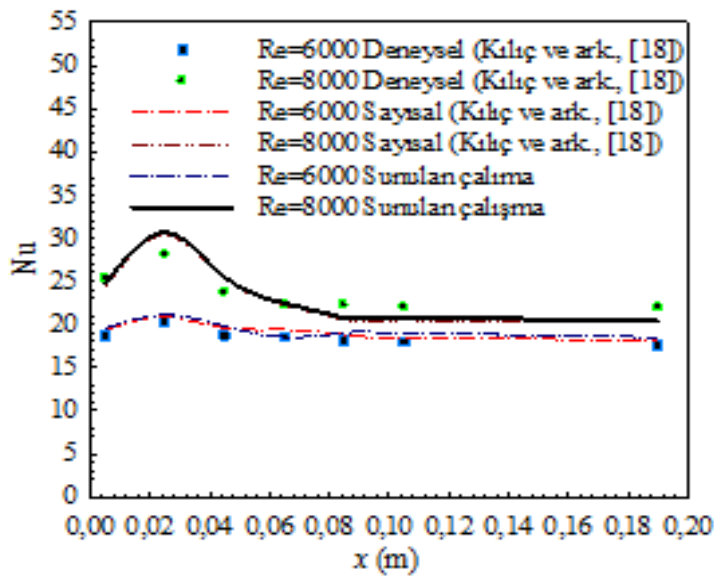

Şekil 2. Sonuçların karşılaştırılması

$\mathrm{H} / \mathrm{D}_{\mathrm{h}}=3$ için desenli yüzeylerin ortalama $\mathrm{Nu}$ sayıları üzerinde ă̆ sayısının etkisini bulmak amacıyla düz yamuk ve ters yarım daire desenli yüzeyler için gerçekleştirilen ağ bağımsızlık incelemeleri sirasıyla Çizelge 1 ve 2'de sunulmaktadır. Ulaşılan sonuçlara göre düz yamuk ve ters yarım daire desenli yüzeylerin bulunduğu kanallar için sırasıyla 1208792 ve 1325054 adet ağ elemanın uygun olduğu saptanmıştır. 
Çizelge 1. Düz yamuk desenli kanal için $\mathrm{Nu}_{\mathrm{o}}$ için ağ bağımsızlık incelemesinin sonuçları

\begin{tabular}{|c|c|c|c|c|}
\hline Ăg sayısı & $\begin{array}{c}\mathrm{Nu}_{\mathrm{o}} \\
\mathrm{Re}=5000\end{array}$ & $\begin{array}{c}\mathrm{Nu}_{\mathrm{o}} \\
\mathrm{Re}=7000\end{array}$ & $\begin{array}{c}\mathrm{Nu}_{\mathrm{o}} \\
\mathrm{Re}=9000\end{array}$ & $\begin{array}{c}\mathrm{Nu}_{\mathrm{o}} \\
\mathrm{Re}=11000\end{array}$ \\
\hline 578142 & 8,09 & 13,24 & 15,47 & 17,24 \\
\hline 1208792 & 11,3 & 14,01 & 16,67 & 18,59 \\
\hline 1684571 & 11,29 & 14,01 & 16,67 & 18,58 \\
\hline
\end{tabular}

Çizelge 2. Ters yarım daire desenli kanal için $\mathrm{Nu}_{\mathrm{o}}$ için ăg bağımsılılık incelemesinin sonuçları

\begin{tabular}{|c|c|c|c|c|}
\hline Ağ say1s1 & $\begin{array}{c}\mathrm{Nu}_{\mathrm{o}} \\
\mathrm{Re}=5000\end{array}$ & $\begin{array}{c}\mathrm{Nu}_{\mathrm{o}} \\
\mathrm{Re}=7000\end{array}$ & $\begin{array}{c}\mathrm{Nu}_{\mathrm{o}} \\
\mathrm{Re}=9000\end{array}$ & $\begin{array}{c}\mathrm{Nu}_{\mathrm{o}} \\
\mathrm{Re}=11000\end{array}$ \\
\hline 624574 & 8,47 & 12,34 & 15,74 & 18,48 \\
\hline 1325054 & 11,25 & 14,81 & 18,15 & 21,23 \\
\hline 1742403 & 11,25 & 14,82 & 18,16 & 21,23 \\
\hline
\end{tabular}

Düz yamuk ve ters yarım daire desenli plakalı hale getirebilmek için yakınlaştırılarak Şekil 3 (a) yüzeylere sahip kanallardaki ağ yapıları, ve (b)'de gösterilmiştir. desenlerdeki ağ yapılarını da kolaylıkla görünür
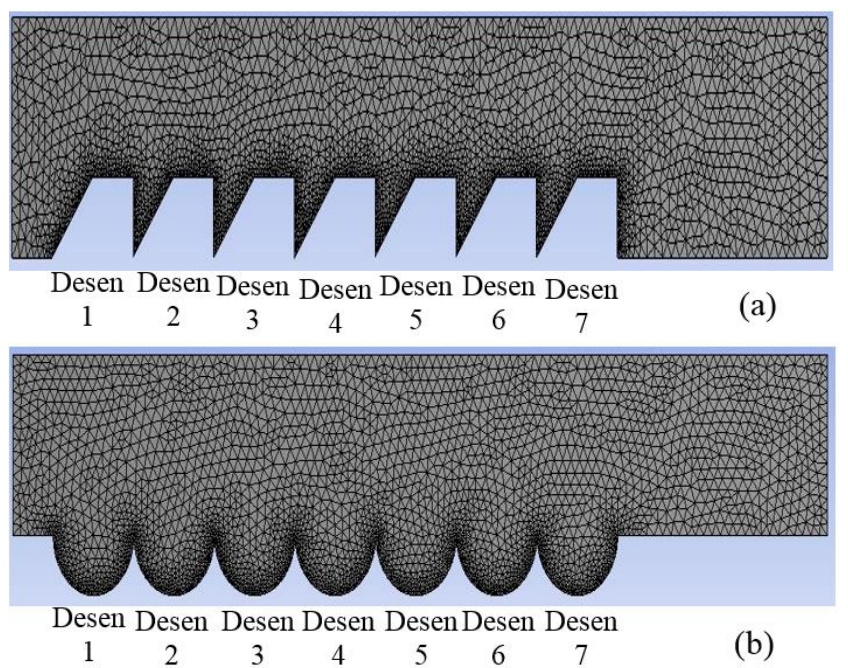

Şekil 3. Hesaplamada kullanılan (a) düz yamuk (b) ters yarım daire desenli yüzeylere sahip kanalların ağ yapilar1

Şekil 4'de $\mathrm{D}_{\mathrm{h}}$ jet giriş genişliğindeki kanallarda sirasiyla A-düz yamuk ve B-ters yarım daire desenli yüzeylere ait (a) $\mathrm{H} / \mathrm{D}_{\mathrm{h}}=6$ (b) $\mathrm{H} / \mathrm{D}_{\mathrm{h}}=12$ jetplaka arası mesafelerde ortalama $\mathrm{Nu}$ sayısının $\mathrm{Re}$ sayısı ile değişimi sunulmaktadır. Kanalların her birinde eşit boyutlarda yedişer adet desenli yüzey bulunmaktadır. Şekil 4A(a)'da öncelikle birinci düz yamuk desenli yüzeye jetin çarpması nedeniyle $\mathrm{Nu}$ sayısında diğer yüzeylere göre daha yüksek bir değer elde edilmektedir. Bununla birlikte, jetin desen geometrisine bağlı olarak diğer yüzeylerde etkisini kaybetmesinin yanı sıra desen aralarına nüfuz edememesi diğer desenlerde $\mathrm{Nu}$ sayısının azalmasına sebep olmaktadır. $\mathrm{H} / \mathrm{D}_{\mathrm{h}}$ mesafesinin 12 değerine çıkması ise desenler üzerinde jet etkisini azaltarak $\mathrm{Nu}$ sayısı değerinin tüm yüzeyler için azalmasıyla sonuçlanmıştır. Şekil 4B'de ters yarım daire desenli yüzeylere ait $\mathrm{Nu}$ sayısı grafiklerine bakıldığında ise düz yamuk desenli yüzeye göre birinci desen için $\mathrm{Nu}$ sayısı 
değeri azalış gösterse de ikinci desenden itibaren $\mathrm{Nu}$ sayısı değerlerinin daha fazla olduğu grafikten kolaylıkla görülebilmektedir. Ayrıca, Şekil 4B (b)'de $\mathrm{H} / \mathrm{D}_{\mathrm{h}}=12$ için kanal içerisindeki jet akış rejiminin değişimi sonucu özellikle ikinci ve
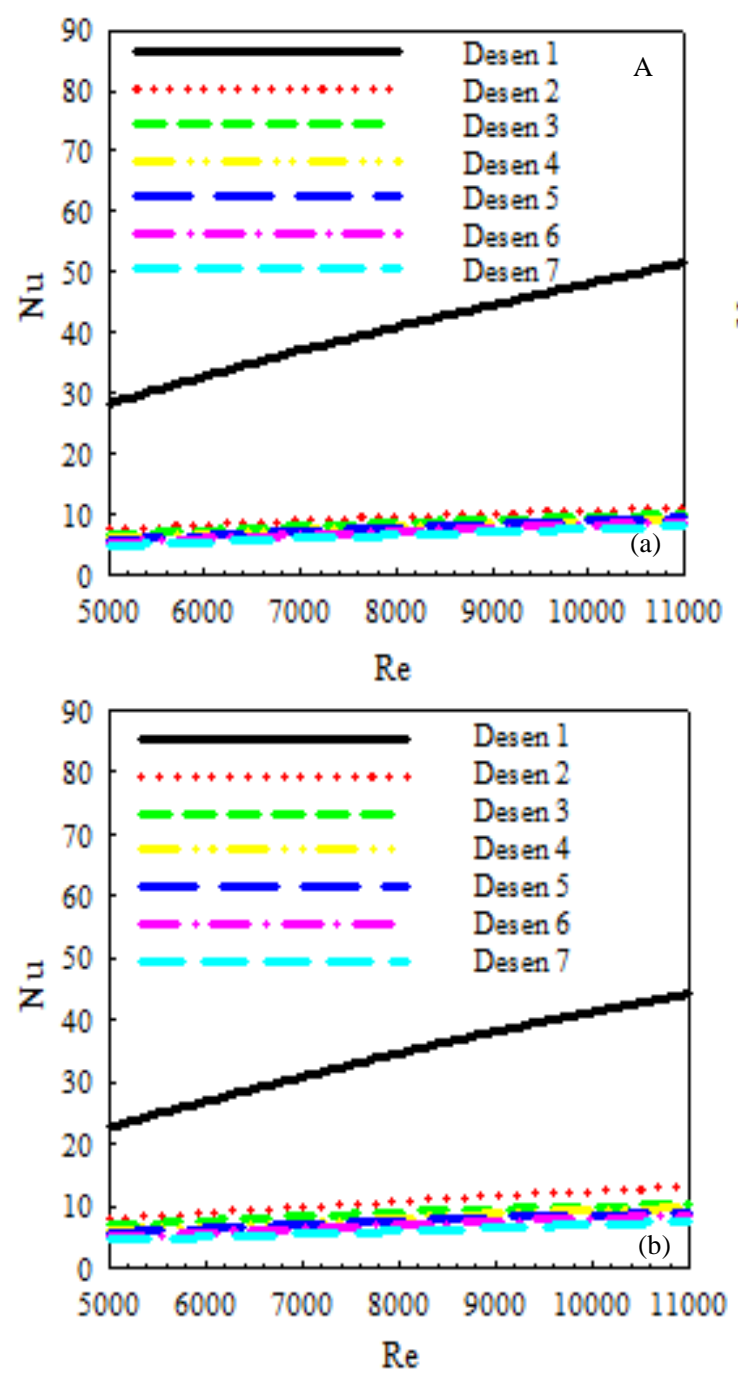

üçüncü desenlere ait $\mathrm{Nu}$ sayısında $\mathrm{H} / \mathrm{D}_{\mathrm{h}}=6$ ' ya göre artışlar elde edilmiştir. $\mathrm{H} / \mathrm{D}_{\mathrm{h}}=12$ ' de $\mathrm{Re}=9000$ için ters yarım daire desenli yüzeylerin ortalama $\mathrm{Nu}$ sayısı değeri, düz yamuk desenli yüzeylerden yaklaşık \%56 daha fazla olmaktadır.
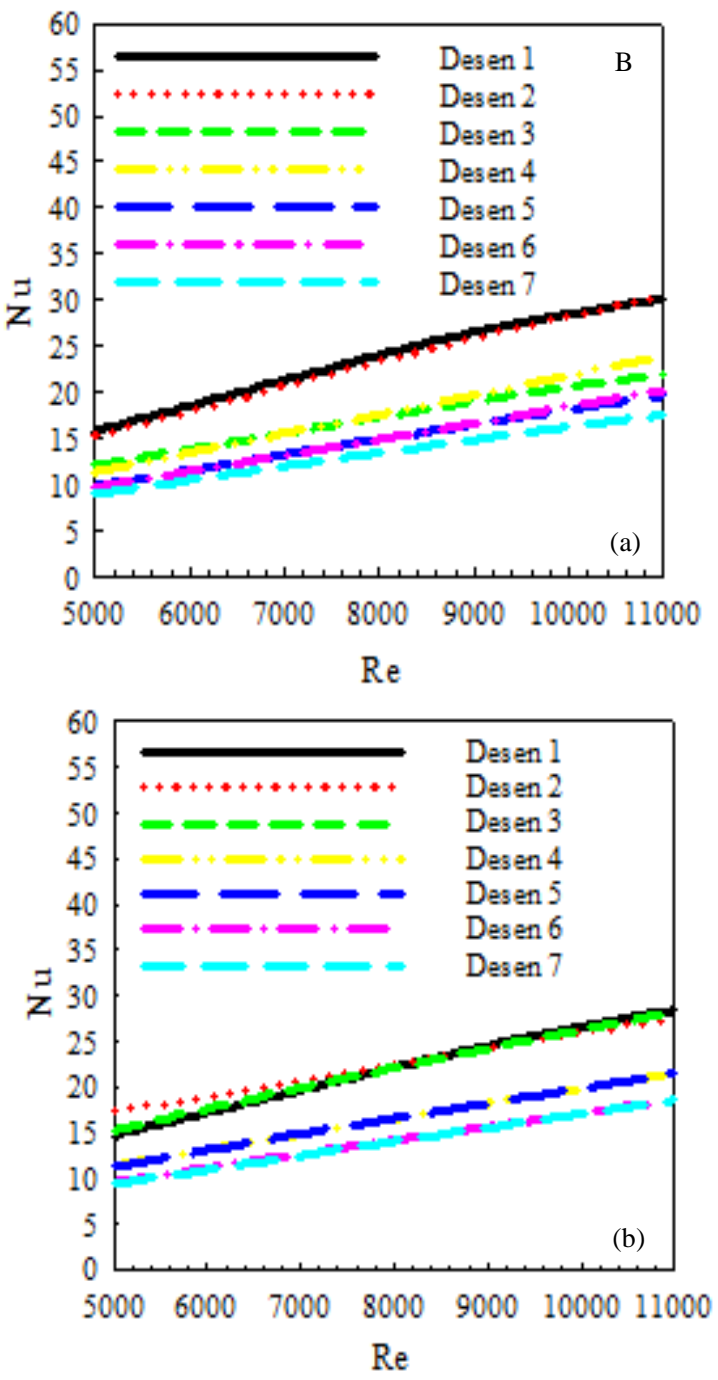

Şekil 4. $a=D_{h}$ için desenlerin ortalama $\mathrm{Nu}$ sayısı değişimi A-düz yamuk B-ters yarım daire desenli yüzey (a) $\mathrm{H} / \mathrm{D}_{\mathrm{h}}=6$ (b) $\mathrm{H} / \mathrm{D}_{\mathrm{h}}=12$

$\mathrm{a}=1,25 \mathrm{D}_{\mathrm{h}}$ jet giriş genişliğine sahip kanallarda bulunan A-düz yamuk ve B-ters yarım daire desenli yüzeylerdeki (a) $H / D_{h}=6$ ve (b) $H / D_{h}=12$ jet-plaka arası mesafelerde Re sayısına bağlı olarak ortalama $\mathrm{Nu}$ sayısı değişimi Şekil 5'de verilmektedir. Jet giriş genişliğinin artışı, sabit Re sayısında jetin kanala giriş hızını azaltmaktadır. Bununla birlikte, bu olumsuz durumun etkisinin azaltılması desenli yüzeylerin geometrik şekline bağlı olarak jetin yüzeylerle olan temasının 
artırılmasına bağlı olmaktadır. Şekil 5A (a) ve (b)'de düz yamuk desenli yüzeylere ait ortalama $\mathrm{Nu}$ sayısı değerleri, $\mathrm{D}_{\mathrm{h}}$ jet giriş genişliğindeki $\mathrm{Nu}$ sayısı değerleri ile karşılaştırıldığında her iki jetplaka arası uzaklık için de değerlerin azalma eğiliminde oldukları görülebilmektedir. Bununla birlikte, Şekil 5B (a)'daki ters daire desenli yüzeyde ise $H / D_{h}=6$ için $D_{h}$ jet giriş genişliğine göre ortalama $\mathrm{Nu}$ sayısı değerlerinde az da olsa azalma görülse de $\mathrm{H} / \mathrm{D}_{\mathrm{h}}=12$ değerine göre ise $1,25 \mathrm{D}_{\mathrm{h}}$ jet genişliğinde $\mathrm{Nu}$ sayısında artış elde edilmektedir. $\mathrm{Bu}$ duruma jet-plaka arası mesafe artışıyla azalan jet etkisine rağmen ters daire desenli yüzeylerde jetin kanal içerisinde değişen akış yapısıyla daha iyi bir şekilde desenlere nüfuz edebilmesinin etkili olduğu düşünülmektedir. $\mathrm{H} / \mathrm{D}_{\mathrm{h}}=6$ ' da $\mathrm{Re}=7000$ ve düz yamuk desenli yüzey için $1,25 \mathrm{Dh}$ jet genişliğinde $\mathrm{D}_{\mathrm{h}}$ jet genişliğine göre ortalama $\mathrm{Nu}$ sayısı \%4,9 azalmaktadır. Aynı şartlarda ters daire desenli yüzey için bu azalma miktarı \%1'in altındadır. Bununla birlikte, $\mathrm{H} / \mathrm{D}_{\mathrm{h}}=12$ için ters daire desenli yüzeyde ve $\mathrm{Re}=11000$ değerinde $\mathrm{D}_{\mathrm{h}}$ jet genişliğine göre $1,25 \mathrm{D}_{\mathrm{h}}$ jet giriş genişliğinde ortalama $\mathrm{Nu}$ sayısında yaklaşık \%6'lık bir artış elde edilmektedir.
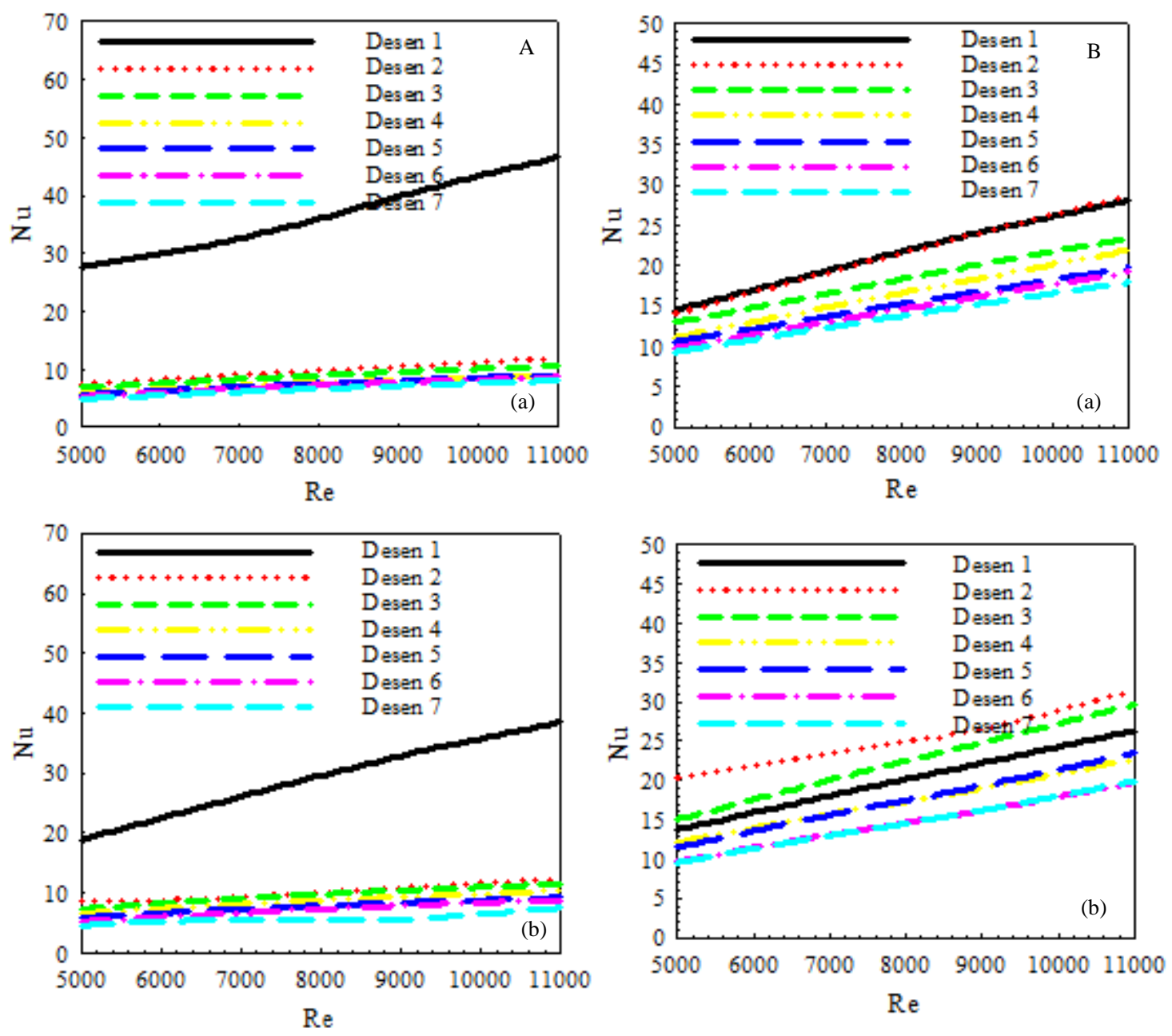

Şekil 5. $\mathrm{a}=1,25 \mathrm{D}_{\mathrm{h}}$ için desenlerin ortalama $\mathrm{Nu}$ sayısı değişimi A-düz yamuk B-ters yarım daire desenli yüzey (a) $\mathrm{H} / \mathrm{D}_{\mathrm{h}}=6$ (b) $\mathrm{H} / \mathrm{D}_{\mathrm{h}}=12$ 
Şekil 6'da A-düz yamuk ve B-ters yarım daire desenli yüzeylere ait $a=D_{h}$ jet giriş genişliğinde (a) $\mathrm{H} / \mathrm{D}_{\mathrm{h}}=6$, (b) $\mathrm{H} / \mathrm{D}_{\mathrm{h}}=12$ jet-plaka arası uzaklıklarında yüzeylerin ortalama sıcaklık değişimleri gösterilmektedir. Jet etkisinin son desene doğru azalması nedeniyle 1s1 transferi en az son desende olmaktadır. Bu nedenle, her iki desen şekli ve $\mathrm{H} / \mathrm{D}_{\mathrm{h}}$ oranlarında en yüksek yüzey sıcaklığ değerine yedinci desende ulaşılmaktadır. Yedinci desenden birinci desene doğru ise $1 \mathrm{~s} 1$ transferinin artışıyla desenli yüzeylerdeki sıcaklıklar azalmaktadır. Bununla birlikte, grafiklerden de görülebildiği gibi düz yamuk desenli yüzeylerdeki sıcaklık değerleri, ters yarım daire desenli yüzeylere göre daha fazladır. Bu durum, ters daire desenli yüzeylerde 1si transferi ve dolayısıyla soğumanın daha iyi olduğunu göstermektedir. $\mathrm{H} / \mathrm{D}_{\mathrm{h}}=6$ için $\mathrm{Re}=7000$ 'de ters yarım daire desenli yüzeylerin ortalama sıcaklığı, düz yamuk desenli yüzeylerden $\% 7,12$ daha düşüktür.
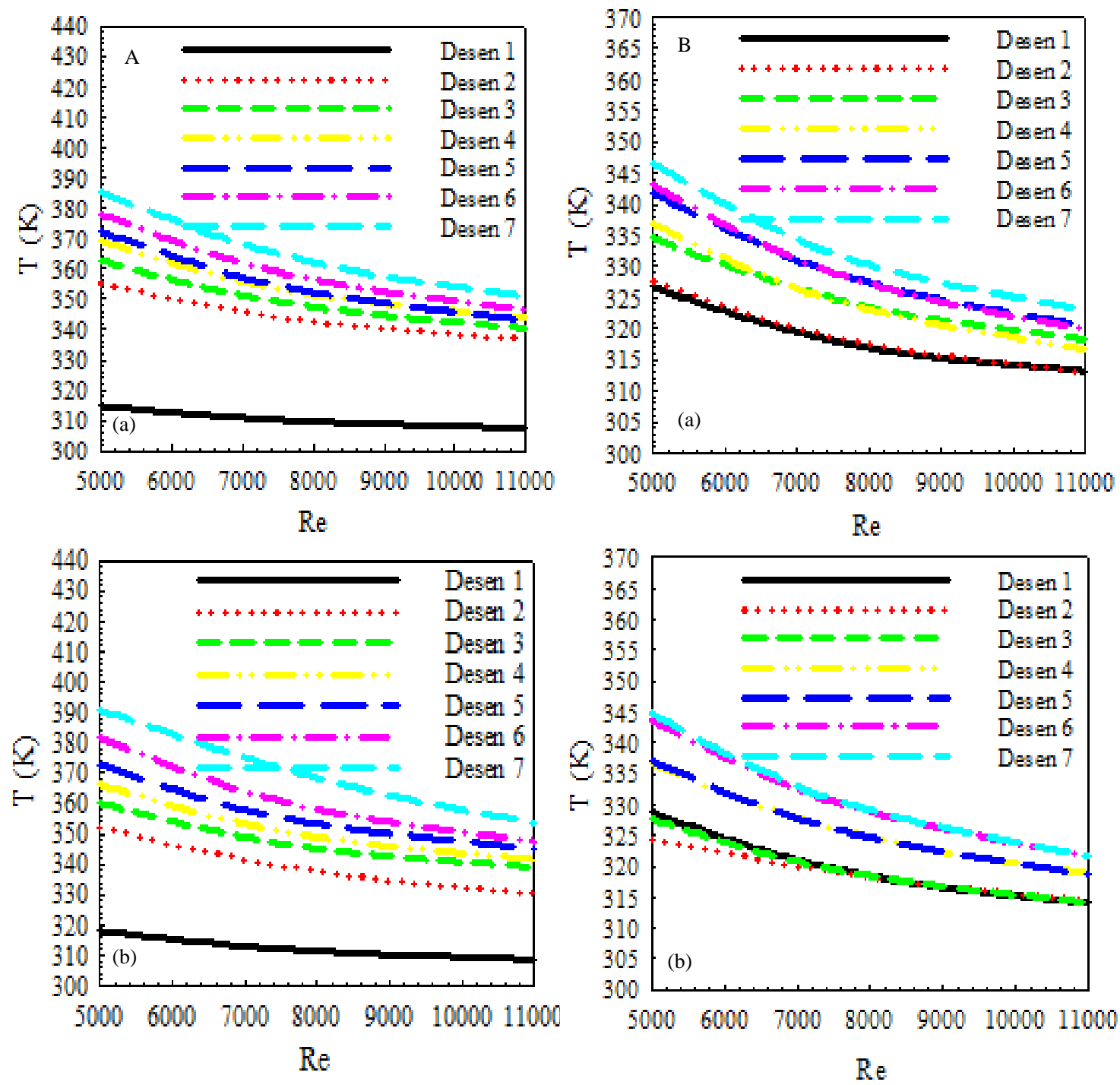

Şekil 6. $a=D_{h}$ için desenlerin ortalama yüzey sıcaklığı değişimi A-düz yamuk B-ters yarım daire desenli yüzey (a) $H / D_{h}=6$ (b) $H / D_{h}=12$ 
$\mathrm{a}=1,25 \mathrm{D}_{\mathrm{h}}$ jet giriş genişliğinde $\mathrm{A}$-düz yamuk ve $\mathrm{B}$ ters yarım daire desenli yüzeylere için (a) $\mathrm{H} / \mathrm{D}_{\mathrm{h}}=6$, (b) $\mathrm{H} / \mathrm{D}_{\mathrm{h}}=12$ jet-plaka arası mesafelerde yüzeylere ait ortalama sıcaklık değişimleri Şekil 7'de sunulmaktadır. Düz yamuk desenli yüzey için jetplaka arası mesafenin artması desenler üzerinde jet etkisini azaltarak yüzey sicaklıklarının artmasına sebep olmaktadır. Bununla birlikte, Şekil 7B (a) ve (b)'ye bakıldığında ise ters daire desenli yüzeylerde düz yamuk desenli yüzeylere göre daha düşük yüzey sıcaklıklarının elde edildiği görülmektedir. Ayrıca, H/D $=6$ için $\mathrm{Re}=7000$ 'de Desen 3 için yüzey sicaklığında düşüş elde edilirken; Re sayısı artırıldığında kanal içerisinde jet akışın yüzey üzerindeki etkisi de azalmış ve bu nedenle yüzey sıcaklığı artmıştır. Re=5000'de $\mathrm{H} / \mathrm{D}_{\mathrm{h}}=12$ ve jet etkisinin en az olduğu yedinci desen için ters yarım daire desenli yüzeyde ortalama yüzey sıcaklığı incelendiğinde düz yamuk desenli yüzeyden yaklaşık $45 \mathrm{~K}$ daha düşük olduğu belirlenmiştir.
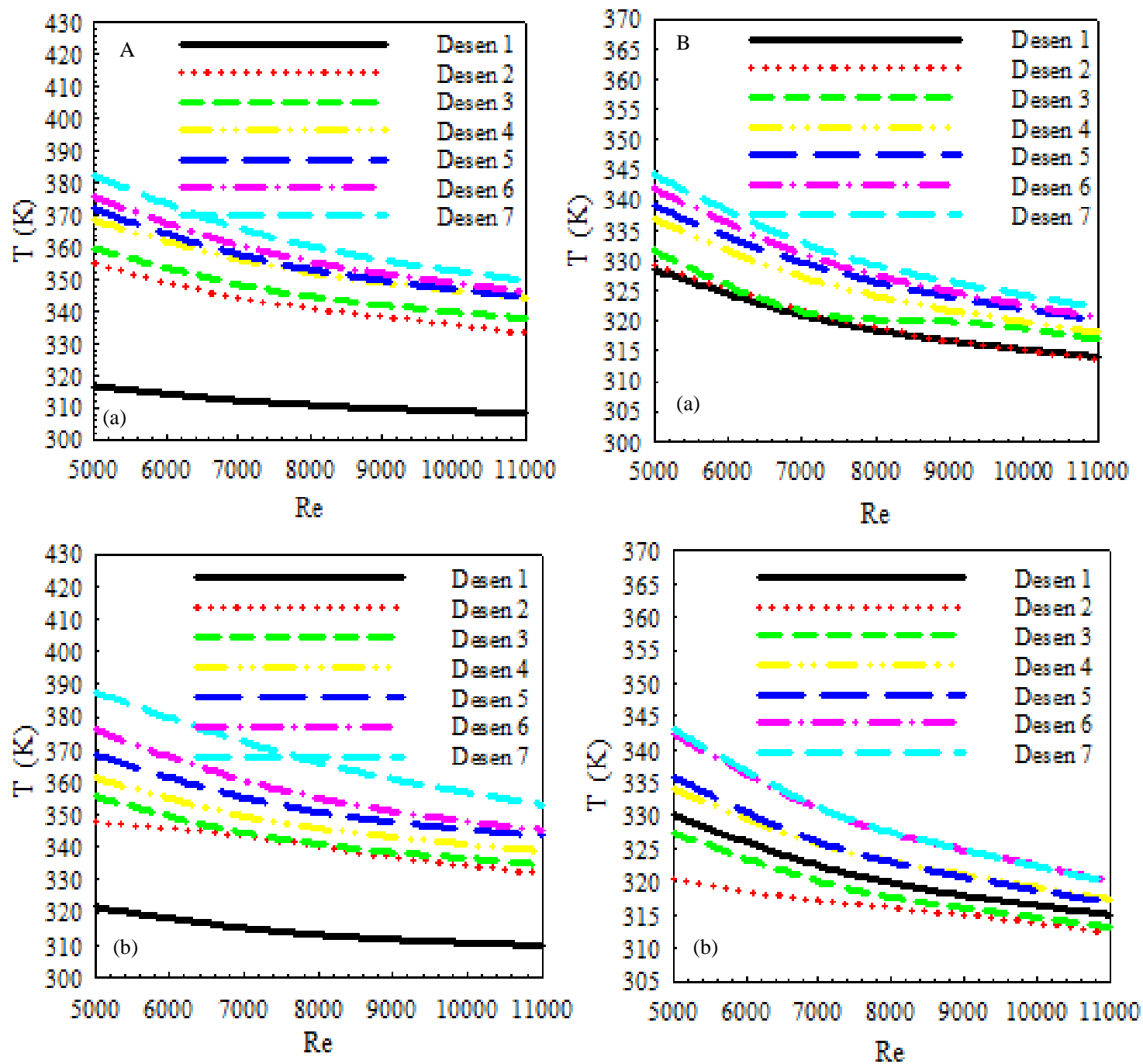

Şekil 7. $\mathrm{a}=1,25 \mathrm{D}_{\mathrm{h}}$ için desenlerin ortalama yüzey sıcaklığı değişimi A-düz yamuk B-ters yarım daire desenli yüzey (a) $\mathrm{H} / \mathrm{D}_{\mathrm{h}}=6$ (b) $\mathrm{H} / \mathrm{D}_{\mathrm{h}}=12$ 
Şekil 8'de $a=D_{h}$ jet giriş genişliğinde $H / D_{h}=3$ ve 6 olmak üzere farklı jet-plaka arası uzaklıklarda $\mathrm{Re}=5000$ için düz yamuk ve ters yarım daire desenli yüzeylerdeki akım çizgisi ve sıcaklık konturu dağılımları gösterilmektedir. Akım çizgisi dağılımı konturlarına bakıldığında, $\mathrm{H} / \mathrm{D}_{\mathrm{h}}=3$ için düz yamuk desenli yüzeylerde desenler arasına jet akışın girişi ters daire desenli yüzeylerden daha zor olduğu için sıcaklık dağılımı konturlarında özellikle desen uçlarında daha yüksek sıcaklıklar elde edilmektedir. Bununla birlikte, her iki desenli yüzey için $H / D_{h}=6$ değerine çıkarıldığında birinci
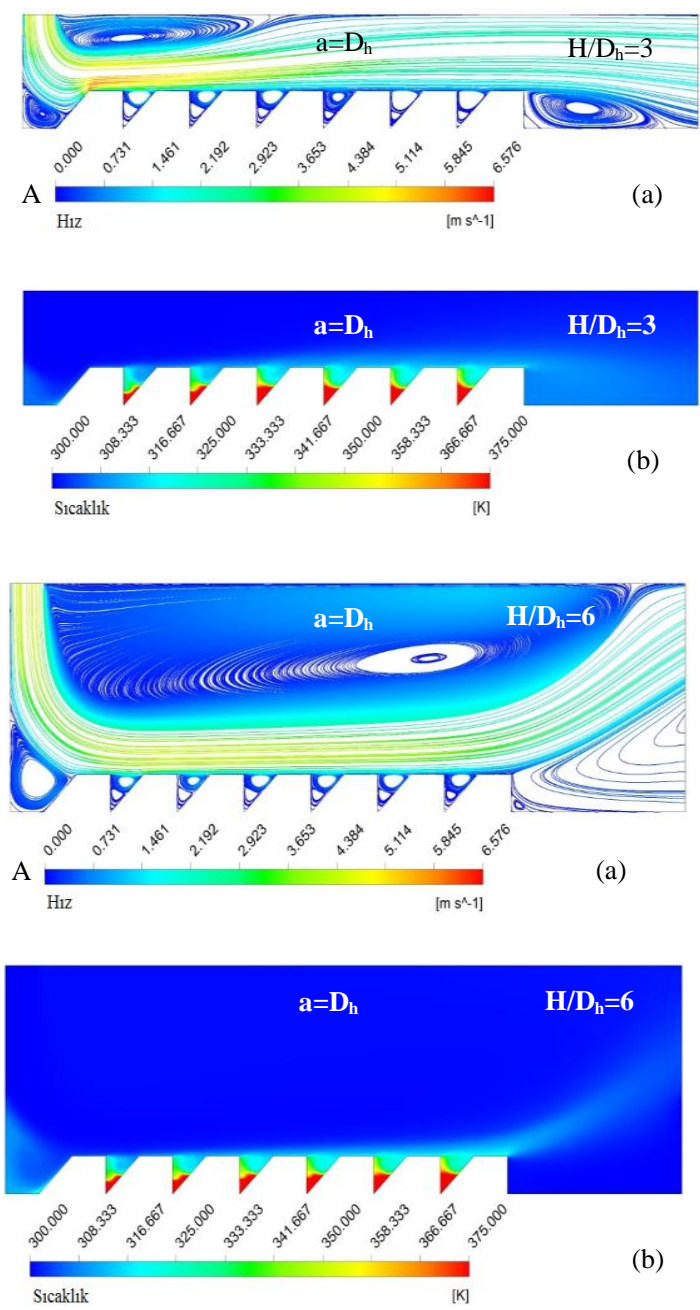

desenlerin sol alt kenarlarında oluşan yeniden dolaşım bölgeleri jet akışın birinci desene olan temasını azalttığından bu desenler etrafında sıcaklıkta artış meydana gelmektedir. Aynı şekilde, kanalın sonundaki yedinci desen etrafında oluşan yeniden dolaşım bölgesi ve jet akışın bu desen üzerindeki etkisinin azalması sıcaklık değerinde artışa neden olmaktadır. Bunun yanı sıra, genel itibariyle sıcaklık konturu dağılımı incelendiğinde ters daire desenli yüzeylerde desenler etrafındaki sıcaklığın düz yamuk desenli yüzeylere göre daha az olduğu görülebilmektedir.
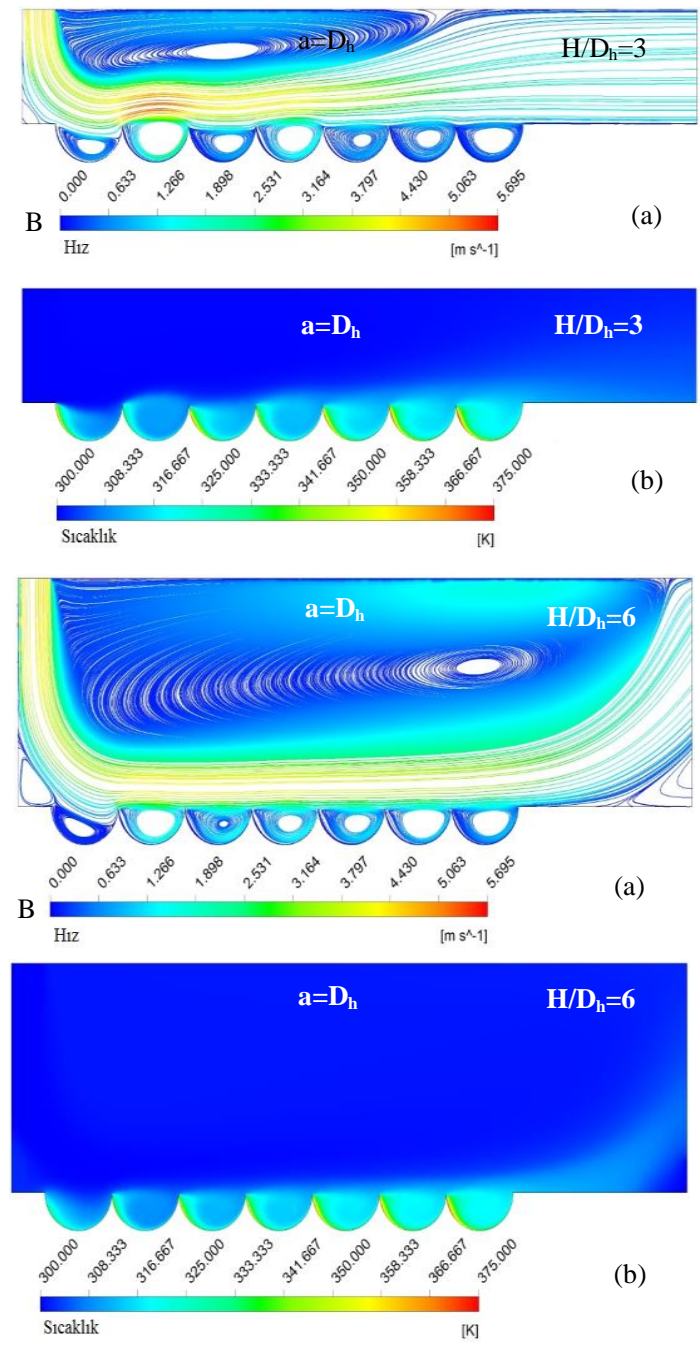

Şekil 8. $a=D_{h}$ jet genişliği ve $R e=5000$ için A-düz yamuk B-ters yarım daire desenli yüzeylerde (a) akım çizgisi (b) sıcaklık konturu dağılımı 
$\mathrm{a}=1,25 \mathrm{D}_{\mathrm{h}}$ jet giriş genişliği ve $\mathrm{Re}=5000$ değerinde düz yamuk ve ters yarım daire desenli yüzeylerdeki akım çizgisi ve sıcaklık konturu dağılımları $\mathrm{H} / \mathrm{D}_{\mathrm{h}}=3$ ve 6 için Şekil 9'da sunulmaktadır. Akım çizgisi konturu dağılımdan görüldüğü gibi jet giriş genişliğinin artırılması $\mathrm{H} / \mathrm{D}_{\mathrm{h}}=3$ için her iki desenli yüzeyde özellikle kanalın girişindeki desenler üzerinde jet hızının

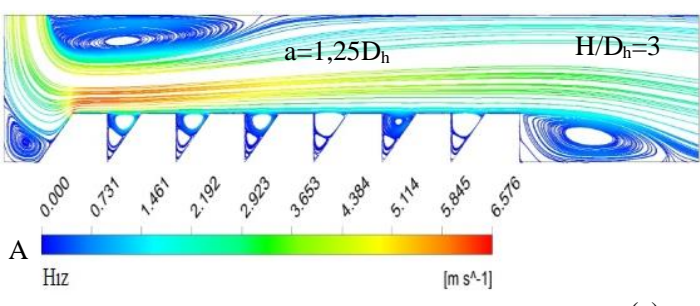

(a)
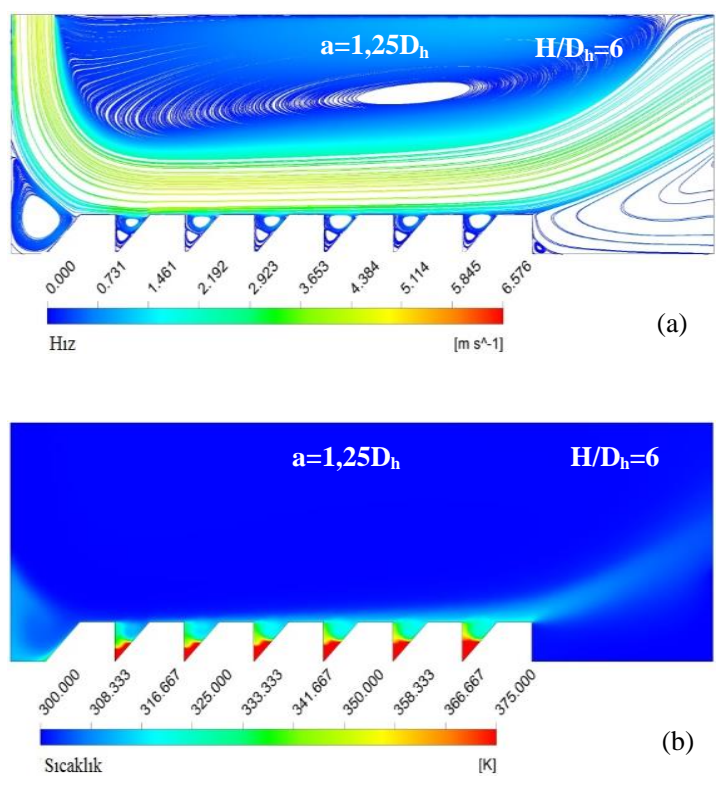

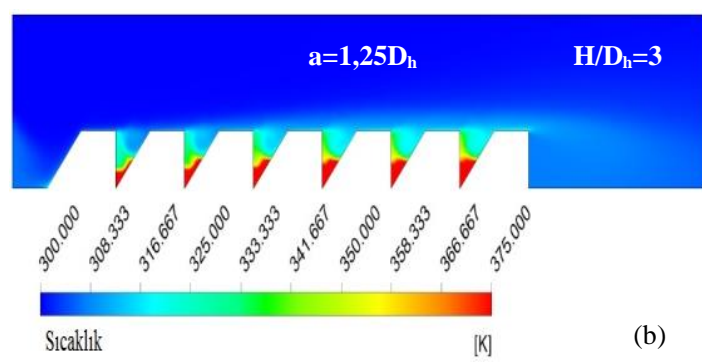

artarak sicaklıklarda azalmaya sebep olmuştur. Bununla birlikte, $1,25 \mathrm{D}_{\mathrm{h}}$ jet giriş genişliğinde $\mathrm{H} / \mathrm{D}_{\mathrm{h}}$ değerinin 6 çıkarılması akışın kanal içerisinde ve özellikle desenler civarında daha düzenli olmasını sağlayarak yeniden dolaşım bölgelerinin etkisini azaltmış olup sıcaklık değerlerinde azalış elde edilmesini sağlamıştır.

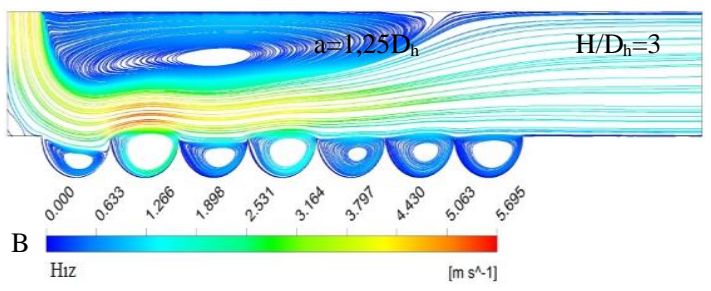

(a)

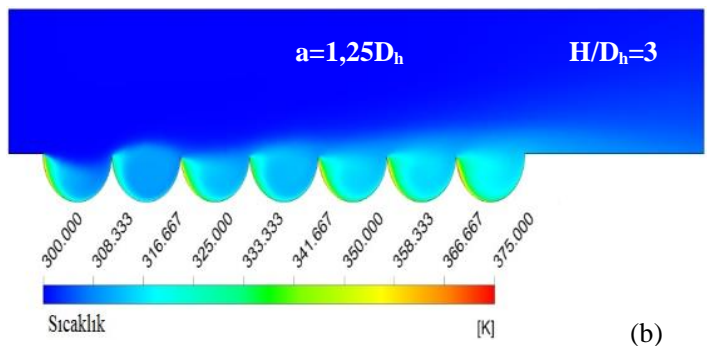

(b)
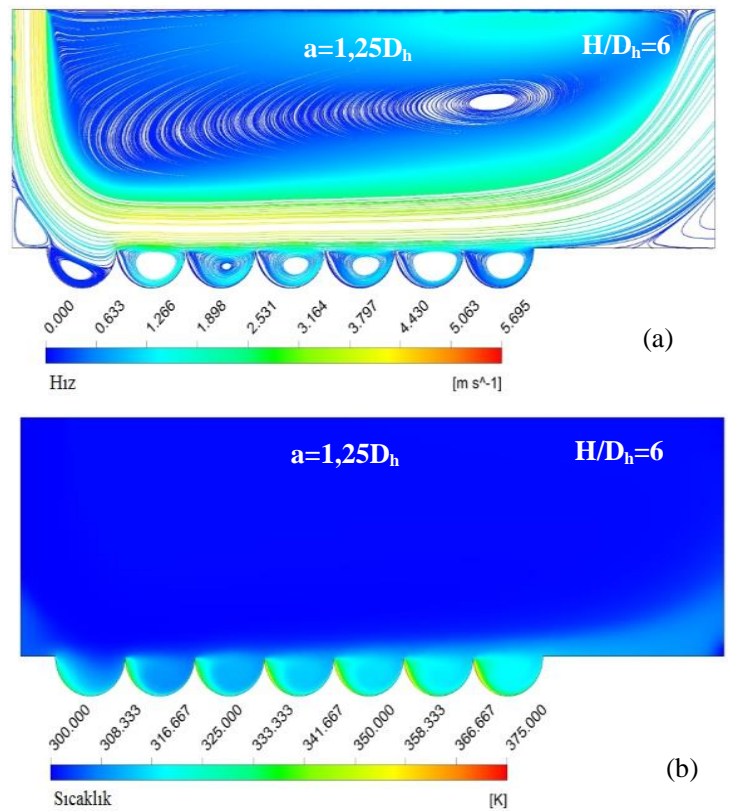

Şekil 9. $\mathrm{a}=1,25 \mathrm{D}_{\mathrm{h}}$ jet genişliği ve $\mathrm{Re}=5000$ için A-düz yamuk B-ters yarım daire desenli yüzeylerde (a) akım çizgisi (b) sıcaklık konturu dağılımı 
Çizelge 3'de $\mathrm{D}_{\mathrm{h}}$ jet giriş genişliği için düz yamuk desenli ve ters yarım daire desenli yüzeyler için yüzeylerin ortalama $\mathrm{Nu}$ sayısı $\left(\mathrm{Nu}_{\mathrm{o}}\right)$ ve jet çıkış sıcaklığı $\left(\mathrm{T}_{\mathrm{jç}}\right) \mathrm{Re}$ sayısı ve $\mathrm{H} / \mathrm{D}_{\mathrm{h}}$ değişimine göre verilmektedir. Her iki desenli yüzey ve $H / D_{h}$ için $\mathrm{Re}$ sayısının artışına bağlı olarak $\mathrm{Nu}$ sayısı değerleri artmaktadır. Bununla birlikte, $\mathrm{Nu}$ sayısının azalması sonucu akışkanın desenli yüzeylerle olan 1sı transferinin gerçekleşme zamanı artacağından jet çıkış sıaklığı $\left(\mathrm{T}_{\mathrm{jç}}\right)$ artmaktadır. Ayrıca, ters yarım daire desenli yüzeylerde daha yüksek $\mathrm{Nu}$ sayısı değerlerine ulaşılırken, $\mathrm{H} / \mathrm{D}_{\mathrm{h}}=12$ için ters yarım daire desenli yüzeylerde akışkanın desenli yüzeyler üzerindeki etkisi arttığından Nu sayısı değerleri de düz yamuk desenli yüzeylere göre artı̧̧ göstermektedir.

Çizelge 3. $a=D_{h}$ jet giriş genişliği için jet akış çıkış sıcaklığ $1\left(T_{j c ̧}\right)$ ve ortalama Nu sayısının değişimi $\left(N_{0}\right)$

\begin{tabular}{|c|c|c|c|c|}
\hline & \multicolumn{2}{|c|}{$\mathrm{H} / \mathrm{D}_{\mathrm{h}}=6$} & \multicolumn{2}{c|}{$\mathrm{H} / \mathrm{D}_{\mathrm{h}}=12$} \\
\hline Düz yamuk desenli yüzey & $\mathrm{T}_{\text {jç }}(\mathrm{K})$ & $\mathrm{Nu}_{\mathrm{o}}$ & $\mathrm{T}_{\text {jç }}(\mathrm{K})$ & $\mathrm{Nu}_{\mathrm{o}}$ \\
\hline $\mathrm{Re}=5000$ & 311,6 & 9,12 & 311,62 & 8,38 \\
\hline $\mathrm{Re}=7000$ & 311,11 & 11,55 & 311,22 & 10,76 \\
\hline $\mathrm{Re}=9000$ & 310,87 & 13,59 & 310,95 & 12,89 \\
\hline $\mathrm{Re}=11000$ & 310,7 & 15,4 & 310,73 & 14,62 \\
\hline \multicolumn{2}{|c|}{$\mathrm{H} / \mathrm{D}_{\mathrm{h}}=6$} & \multicolumn{2}{c|}{$\mathrm{H} / \mathrm{D}_{\mathrm{h}}=12$} \\
\hline Ters yarım daire desenli yüzey & \multicolumn{2}{|c|}{$\mathrm{Nu}_{\mathrm{o}}$} & $\mathrm{T}_{\text {jç }}(\mathrm{K})$ & $\mathrm{Nu}_{\mathrm{o}}$ \\
\hline $\mathrm{Re}=5000$ & 313,39 & 11,86 & 310,62 & 12,64 \\
\hline $\mathrm{Re}=7000$ & 312,39 & 15,94 & 310,41 & 16,38 \\
\hline $\mathrm{Re}=9000$ & 311,88 & 19,91 & 310,3 & 20,01 \\
\hline $\mathrm{Re}=11000$ & 311,59 & 23,51 & 310,25 & 23,47 \\
\hline
\end{tabular}

\section{SONUÇLAR VE TARTIŞMA}

Her geçen gün ilerleyen teknolojik gelişmeler sayesinde boyutları küçülüp, performansları artan elektronik cihazların ısıl yükleri de artmaktadır. Bu durum, aynı zamanda yeni nesil teknolojik elemanların soğutma kapasitelerinin artırılmasını da gerekli kılmaktadır. Aksi halde, yüksek güç yoğunluklu elektronik elemanların elektriksel performans güvenilirliklerinin azalması ve bunlarda oluşacak isıl gerilmeler sonucu fiziksel hasarların meydana gelmesi önlenemez bir sonuç haline gelecektir. Bu sorunları ortadan kaldırmak için kullanılabilecek çarpan jet tekniği, 1S1 üretimleri fazla olan cihazlardaki 1sı transferi miktarını artırmak amaçlı yüksek verimli bir soğutma teknolojisidir.

$\mathrm{Bu}$ amaçla bu çalışmada, iki farklı genişlikte bir tane jet akışı kullanılarak dikdörtgen kesitli kanallar içerisinde bulunan sabit 1s1 akısıyla 1sıtılmış düz yamuk ve ters yarım daire desenli yüzeyler olmak üzere iki farklı şekilden oluşan bakır plakalı yüzeyler için ısı transferi ve kanallar içerisindeki akış yapıları sayısal hesaplamalı olarak araştırılmıştır. Buna göre, bu çalışmada ulaşılan sonuçlar aşağıda özetlenmiştir:

- Genel itibariyle, desenli şekillerin her ikisi için de Re sayısının artışıyla $\mathrm{Nu}$ sayısı artış sergilemektedir.

- $D_{h}$ jet giriş genişliğinde ve $H / D_{h}$ mesafelerinde en yüksek Nu sayısına her iki desenli yüzey için birinci desende ulaşılmaktadır. Bununla birlikte, düz yamuk desenli yüzeyde jetin desen aralarına nüfuz edememesi diğer desenlerde $\mathrm{Nu}$ sayısının azalmasına sebep olmaktadır. Ters yarım daire desenli yüzeylerde ise birinci desenden itibaren diğer desenlerde $\mathrm{Nu}$ sayısında artışlar elde edilmektedir.

- H/D mesafesinin artırılması, $a=D_{h}$ için düz yamuk desenli yüzeylerde desenler üzerinde jet etkisini azaltarak $\mathrm{Nu}$ sayısı değerini tüm yüzeyler için azaltmaktadır. Ters yarım daire desenli yüzeylerde ise kanal içerisindeki jet akış rejiminin değişimi sonucu özellikle ikinci ve üçüncü desenlere ait $\mathrm{Nu}$ sayısında $\mathrm{H} / \mathrm{D}_{\mathrm{h}}=6$ ' ya göre artışlar elde edilmiştir. 
- $a=D_{h}$ ve $H / D_{h}=12$ 'de $R e=9000$ için ters yarım daire desenli yüzeylerin ortalama $\mathrm{Nu}$ sayısı değeri, düz yamuk desenli yüzeylerden yaklaşık \%56 daha fazla olmaktadır.

- $\mathrm{a}=1,25 \mathrm{D}_{\mathrm{h}}$ ve $\mathrm{H} / \mathrm{D}_{\mathrm{h}}=6$ ' da $\mathrm{Re}=7000$ ve düz yamuk desenli yüzey için $a=D_{h}$ jet giriş genişliğine göre ortalama $\mathrm{Nu}$ sayısı \%4,9 azalmaktadır. Aynı şartlarda ters daire desenli yüzey için bu azalma miktarı \%1'in altındadır. Bununla birlikte, $\mathrm{H} / \mathrm{D}_{\mathrm{h}}=12$ için ters daire desenli yüzeyde ve $R e=11000$ değerinde $D_{h}$ jet giriş genişliğine göre $1,25 \mathrm{D}_{\mathrm{h}}$ jet giriş genişliğinde ortalama $\mathrm{Nu}$ sayısında yaklaşık \%6'lık bir artış elde edilmektedir.

- $a=D_{h}$ jet giriş genişliğinde, jet etkisinin son desene doğru azalması nedeniyle 1sı transferi en az son desende olmaktadır. Bu nedenle, her iki desen şekli ve $H / D_{h}$ oranlarında en yüksek yüzey sıcaklığı değerine yedinci desende ulaşılmaktadır. Yedinci desenden birinci desene doğru ise 1s1 transferinin artışıyla desenli yüzeylerdeki sicaklıklar azalmaktadır.

- $a=D_{h}$ jet giriş genişliği ve $H / D_{h}=6$ için $R e=7000$ ' de ters yarım daire desenli yüzeylerin ortalama sıcaklığ 1 , düz yamuk desenli yüzeylerden $\% 7,12$ daha düşüktür.

$-a=1,25 D_{h}$ jet giriş genişliğinde ise $R e=5000$ ' de $\mathrm{H} / \mathrm{D}_{\mathrm{h}}=12$ ve jet etkisinin en az olduğu yedinci desen için ters yarım daire desenli yüzeyde ortalama yüzey sıcaklığı incelendiğinde düz yamuk desenli yüzeyden yaklaşık $45 \mathrm{~K}$ daha düşük olduğu belirlenmiştir.

-Sonuç itibariyle, jet akışı ile desenli yüzeylerden olan 1S1 transferi sonucu soğutma etkisi ve kanaldaki akış yapısı, jet $\mathrm{Re}$ sayısından, $\mathrm{H} / \mathrm{D}_{\mathrm{h}}$ mesafesinden, desenli yüzey şekillerinden ve jet giriş genişliğinden önemli ölçüde etkilenmektedir. Bunun yanı sıra, çalışmada kullanılan ve düz yamuk desenli yüzeye göre daha iyi 1sı transferi sonuçları elde edilen, $1,25 \mathrm{D}_{\mathrm{h}}$ jet giriş genişlikli kanaldaki ters yarım daire desenli yüzey geometrik şekillerinin özellikle bilgisayar işlemcisi gibi yüksek 1s1 üreten elektronik elemanlara benzerlikleri nedeniyle bu elektronik devre elemanlarının soğutulmasında kullanılabilecekleri öngörülmektedir.

\section{KAYNAKLAR}

1. Sharma, S., 2015. Experimental Investigation on Heat Transfer Characteristics from Liquid Jet Impingement to Different Flat Plates, International Journal for Innovative Research in Science \& Technology, 1(12), 130-133.

2. Babic, D., Murray, D.B., Torrance, A.A., 2005. Mist Jet Cooling of Grinding Processes, International Journal of Machine Tools and Manufacture, 45, 1171-1177.

3. Royne,, A., Dey, C., 2004. Experimental Study of A JetI Impingement Device for Cooling of Photovoltaic Cells Under High Concentration, ANZSEZ Solar 2004: Life, the Universe and Renewables Congress, Perth, Australia.

4. Narumanchi, S.V.J., Amon, C.H., Murthy, J.Y., 2003. Influence of Pulsating Submerged Liquid Jets on Chip-Level Thermal Phenomena, Transactions of the ASME, 125(3), 354-361.

5. Kercher, D.S., Lee, J.B., Brand, O., Allen, M.G., Glezer, A., 2003. Microjet Cooling Devices for Thermal Management of Electronics, IEEE Transactions on Components and Packaging Technologies, 26(2), 359-366

6. Carlomagno, G.M., Ianiro, A., 2014. ThermoFluid-Dynamics of Submerged Jets Impinging at Short Nozzle-to-Plate Distance: A Review, Experimental Thermal and Fluid Science, 58, 15-35.

7. Argus, E., Rady, M.A., Nada, S.A., 2006. A Numerical Investigation and Parametric Study of Cooling an Array of Multiple Protruding Heat Sources by A Laminar Slot Air Jet, International Journal of Heat and Mass Transfer, 28, 787-805.

8. Popovac, M., Hanjalic, K., 2007. Large-Eddy Simulation of Flow Over A Jet-impinged Wall Mounted Cube in A Cross Stream, International Journal of Heat and Fluid Flow, 28(6), 1360-1378.

9. Yang, Y.T., Hwang, C.H., 2004. Numerical Simulations on the Hydrodynamics of A Turbulent Slot Jet on A Semi-Cylindrical 
Convex Surface, Numerical Heat Transfer, 46, 995-1008.

10. Karabulut, K., Alnak, D.E., 2020. Değişik Şekilde Tasarlanan Isıtılmış Yüzeylerin Hava Jeti Çarpmalı Soğutulmasının Araştırılması, Pamukkale Üniversitesi, Mühendislik Bilimleri Dergisi, 26(1), 88-98.

11. Karabulut, K., 2019. Heat Transfer Improvement Study of Electronic Component Surfaces Using Air Jet Impingement, Journal of Computational Electronics, 18, 1259-1271.

12. Mushatat, K.S., 2007. Analysis of the Turbulent Flow and Heat Transfer of the Impingement Cooling in A Channel with Cross Flow, Engineering Science, 18(2), 101-122.

13. Tepe, A.Ü., 2021. Numerical Investigation of A Novel Jet Hole Design for Staggered Array Jet Impingement Cooling on A Semicircular Concave Surface, International Journal of Thermal Sciences, 162, 106792.

14. Belarbi, A.A., Beriache, M., Bettahar, A., 2018. Experimental Study of Aero-Thermal Heat Sink Performances Subjected to Impinging Air Flow, International Journal of Heat and Technology, 36(4), 1310-1317.

15. Leena, R., Syamkumar, G., Prakash, M.J., 2018. Experimental and Numerical Analyses of Multiple Jets Impingement Cooling for High-power Electronics, IEEE Transactions on Components Packaging and Manufacturing Technology, 8(2), 210-215.

16. Wang, S.J., Mujumdar, A.S., 2005. A Comparative Study of Five Low Reynolds Number $\mathrm{k}-\varepsilon$ Models for Impingement Heat Transfer. Applied Thermal Engineering, 25, 31-44, 2005.

17. Saleha, N., Fadela, N., Abbes, A., 2015. Improving Cooling Effectiveness by Use Chamfers on the Top of Electronic Components, Microelectronics Reliability, 55, 1067-1076.

18. Kılıç, M., Çalışır, T., Başkaya, Ş., 2017. Experimental and Numerical Study of Heat Transfer from a Heated Flat Plate in a Rectangular Channel with an Impinging Air Jet, Journal of Brazilian Society of Mechanical Sciences and Engineering, 39(1), 329-344. 
